\title{
Temporal variation in coral reef ecosystem processes: herbivory of macroalgae by fishes
}

\author{
Carine D. Lefèvre ${ }^{*}$, David R. Bellwood \\ Australian Research Council Centre of Excellence for Coral Reef Studies and School of Marine and Tropical Biology, \\ James Cook University, Townsville, Queensland 4811, Australia
}

\begin{abstract}
Despite the widely accepted importance of fish herbivory on coral reefs, few studies have considered the temporal variability in the nature of algal-herbivore interactions. We therefore quantified monthly feeding intensity on Sargassum sp. bioassays for 12 mo with remote underwater video cameras deployed to identify the herbivores responsible for macroalgal removal on an inshore island of the Great Barrier Reef, Australia. Significantly higher removal rates were observed during the summer months whereas winter months were characterized by 4 times lower removal rates. However, rather than being simply changes in the feeding activity of a single species, this temporal pattern in herbivory also incorporated changes in the species responsible for the removal of Sargassum. Video analyses revealed that, of the 43 herbivore species recorded from the bay, only 3 played a significant role in Sargassum removal: Kyphosus vaigiensis, Naso unicornis and Scarus rivulatus. $K$. vaigiensis, a rudderfish, was primarily responsible for the removal of Sargassum during the summer months (83\% of the total recorded bites; 85553 bites). There was almost no feeding activity on Sargassum by $K$. vaigiensis during the winter months (82 bites). However, there was a reciprocal increase in feeding intensity on Sargassum by parrotfishes in the winter months, particularly S. rivulatus (71 bites during summer versus 2884 bites in winter). This temporal variability in herbivore functional roles suggests that functional redundancy on reefs may be less than previously assumed in that the feeding activities of fishes may be both spatially and temporally constrained.
\end{abstract}

KEY WORDS: Regime shift - Kyphosus vaigiensis · Trophic status · Phase shift • Resilience • Functional redundancy $\cdot$ Macroalgae $\cdot$ Sargassum $\cdot$ Great Barrier Reef

\section{INTRODUCTION}

Herbivores are widely considered to be integral to the maintenance of healthy coral reef ecosystems (e.g. Choat 1991, Hughes et al. 2003, Mumby et al. 2006). Recently, the degradation of reefs and subsequent loss of resilience has further highlighted the role and overwhelming importance of herbivorous reef fishes in mediating the transition from a healthy, coraldominated state to a less desirable, degraded macroalgal-dominated system (Hughes 1994, McClanahan et al. 2001, Pandolfi et al. 2003, Bellwood et al. 2004, 2006, Graham et al. 2006, Mumby et al. 2006, Hughes et al. 2007). The alarming decline of coral reefs has therefore led to calls for the active monitoring and management of coral reef resilience (Bellwood et al. 2004, Hughes et al. 2010). There is an urgent need to understand the process of herbivory from the point of view of individual species, based on an integrated knowledge of their interactions with macroalgal populations, their ability to consume and remove macroalgae under equilibrium conditions and their potential ability to remove macroalgae under alternate states (Bellwood et al. 2004, 2006, Hughes et al. 2007). Herbivorous fishes confer ecosystem resilience in that they regulate the balance between corals and macroalgae, and thus help the reef to withstand impacts or regenerate following disturbance events (Nyström et al. 2000, Jackson et al. 2001, Nyström \& Folke 2001, Bellwood et al. 2004). The resilience of a reef is therefore highly 
dependent on the contribution of the key functional elements and the composition of the herbivore community.

Algal assemblages on the Great Barrier Reef (GBR) show marked cross-shelf and within-reef variations in composition and abundance (e.g. Wismer et al. 2009). In contrast to mid-shelf and outer-shelf reefs, inshore or coastal reefs typically have abundant and conspicuous macroalgal communities (Diaz-Pulido et al. 2007, Wismer et al. 2009). The reef flat zone in particular is often dominated by dense beds of large fleshy brown macroalgae, predominantly Sargassum sp. (Fucales, Phaeophyta) (e.g. McCook 1997, Schaffelke \& Klumpp 1997). Several experimental studies based on the exclusion of herbivorous fishes from reef areas have highlighted the importance of macroherbivores in controlling not only the abundance of benthic macroalgae species but also the distribution patterns of algal communities (McClanahan et al. 2003, Russ 2003, Ceccarelli et al. 2006, Hughes et al. 2007). Such experimental studies have also identified the negative effect of Sargassum on corals, reducing coral settlement and undermining regeneration after bleaching (Hughes et al. 2007). However, despite a growing interest in examining functional groups among coral reef species, few studies have documented the relative functional impacts of individual herbivorous fish species in underpinning the health of coral reef ecosystem processes, particularly in the Indo-Pacific (but see Bellwood et al. 2006, Fox \& Bellwood 2008b, Hoey \& Bellwood 2009, 2010b). In this context, fine-scale studies on the potential functional role of individual herbivore species and thus the contribution of species in removing macroalgae have become an important prerequisite to the development of effective strategies for protecting and managing coral reef ecosystems.

Fine-scale studies on functional groups, identifying and quantifying ecosystem impacts of individual herbivorous taxa on coral reefs, will thus provide crucial information on the extent of functional redundancy (the ability of one group to substitute for another in a given functional role) and potential coral reef resilience (Bellwood et al. 2003, Hughes et al. 2003, Wilson et al. 2006). Until recently, herbivory was largely treated as a homogeneous process and the identity of the species responsible for the removal of transplanted algal material was not considered critical (e.g. Reinthal \& Macintyre 1994). This approach, using algal transplants only, was limited by the inability to attribute macroalgal assay removal to particular taxa and overlooked the potential variety of functional impacts of different herbivore species. Most studies have indeed assumed functional roles based on visual counts or assays with no videos. However, several recent studies have demonstrated that grazing activity of distinct groups within the herbivore guild have significantly different effects on the algal community succession (e.g. Hixon \& Brostoff 1996, Ceccarelli et al. 2005a, Hoey \& Bellwood 2010a), with individual species having markedly different functional roles (e.g. Bellwood et al. 2006, Hoey \& Bellwood 2008). Recent evidence using remote video cameras has also revealed that direct observations may influence fish behaviour and feeding activity, especially by macroalgal browsers (Fox \& Bellwood 2008a). Remote underwater video technology has provided a useful tool for quantifying the impact of individual species by significantly reducing the effects of a diver's presence. Observations with underwater video cameras provide an opportunity to not only identify the species responsible for macroalgal removal but also to quantify the magnitude of the role played by the various species in macroalgae removal at different locations or times of the year (Hoey \& Bellwood 2009).

Until recently, almost all studies describing functional roles of herbivorous fishes have advocated an approach where functional roles are viewed as a species-specific trait. Although we now recognize the potential extent of ontogenetic changes (Bonaldo \& Bellwood 2008), few studies have raised the possibility that the role of these herbivores may vary over the year. McCook (1997) and Paddack et al. (2006) are notable exceptions, but in each case they only made use of either cages versus uncaged macroalgal transplants or visual observations, respectively. Previous studies on the GBR have identified marked seasonal variation in the removal of macroalgae, probably by fishes, but the species responsible were not identified (Lefèvre \& Bellwood 2010). Virtually nothing is known of intraspecific temporal variation in the functional role of herbivorous reef fish species on Indo-Pacific reefs. Evaluating the extent to which herbivorous species remove Sargassum at various time of year can help link changes in fish community structure to effects on ecological functions, predict the ability of a reef to withstand disturbances and identify crucial functional groups in order to avoid coral-algal phase shifts. This gap in our understanding of herbivory therefore raises the question: do temporal dynamics of Sargassum reflect changes in the functional role of Sargassumfeeding fishes on coral reefs and, if so, to what extent?

The specific aim of the present study was to investigate whether variation in macroalgal removal rates throughout the year are associated with changes in herbivore functional groups over time or merely variation in feeding activity of a single species (or group of species). To answer this question, a combination of transplanted macroalgal assays and remote underwater videos was used in order to quantify the relative importance of individual herbivorous species in macroalgal removal among months. 


\section{MATERIALS AND METHODS}

Study sites. The study was conducted between January and December 2008 on Orpheus Island $\left(18^{\circ} 35^{\prime} \mathrm{S}\right.$, $146^{\circ} 20^{\prime} \mathrm{E}$ ) in the inner shelf region of the central GBR, $\sim 20 \mathrm{~km}$ from the North Queensland coast. To quantify temporal variation in the feeding intensity of herbivorous fishes, 2 sites were selected within Pioneer Bay, located on the reef crest (depth of 3 to $5 \mathrm{~m}$ ), as grazing intensity has been reported to be the highest in this reef zone (Hoey \& Bellwood 2008).

Relative contribution of herbivorous fish species. Transplanted algal bioassays and remote stationary underwater digital video cameras were used to determine temporal variability in the relative contribution of individual herbivorous fish to algal removal. The macroalgae used for this project was from the genus Sargassum (Phaeophyceae: Sargassaceae), previously used in transplant experiments (McCook 1996, Cvitanovic \& Bellwood 2009, Hoey \& Bellwood 2009). This genus represents one of the most common and conspicuous form of fleshy seaweeds found on the inner shelf of the GBR. Sargassum species are notorious for their confusing and poorly understood taxonomy (Kilar et al. 1992) and, as a result, it was not possible to identify the morph used in our study to species level. The Sargassum in the sampling sites was, however, dominated by a single morph. Therefore, the single dominant morph was used exclusively throughout the present study in order to avoid potential interspecific differences in Sargassum phenology and nutritional characteristics that could confound seasonal patterns.

The transplant method for Sargassum collection, weighing and deployment follows Lefèvre \& Bellwood (2010). Briefly, Sargassum plants were collected along the inner and mid intertidal reef flat (depth of 0 to $3 \mathrm{~m}$ ), ensuring that the holdfast was intact, and were kept in outdoor, recirculating seawater raceways until they were used in transplant experiments (within 12 to $36 \mathrm{~h}$ of collection). Proportional-sized algal specimens were chosen to represent algae in their natural condition (i.e. representing the phenological patterns over the year) in order to compare treatment effects at different times of the year. The maximum length of the primary axis and wet weight to the nearest $1 \mathrm{mg}$ (after spinning for $10 \mathrm{~s}$ in a salad spinner) of algal assays were recorded before exposure. The assays were then haphazardly deployed at each site and were filmed using remote video cameras. At each site, one Sargassum transplant was secured to the reef on coral rubble, using wire threaded through an elastic band around the holdfast. Care was taken to hide the wire in order to minimise its impact on feeding behaviour. The camera was mounted on a cement block positioned $\sim 2 \mathrm{~m}$ from the transplanted macroalgae. The assays were filmed for a $4.5 \mathrm{~h}$ experimental period between 8:00 and 13:00 h. The camera was set to record for a few moments with a tag in the field of view to provide a size and identification frame of reference when viewing the footage. Tape and battery changes were required every $90 \mathrm{~min}$, but interruption to filming was minimised to less than $5 \mathrm{~min}$. This procedure was replicated on 3 separate days resulting in a total of $27 \mathrm{~h}$ of video footage between the 2 sites every month $(12 \mathrm{mo}$; total of $324 \mathrm{~h})$. After $4.5 \mathrm{~h}$, the algal assays were collected, transported to the laboratory, and immediately weighed and measured. Feeding intensity was calculated in terms of the standardized percentage of biomass loss (allowing for the macroalgal mass lost from assays as a result of handling; see Lefèvre \& Bellwood 2010) and percentage decrease in thallus length observed for each replicate after $4.5 \mathrm{~h}$ of exposure.

Video analyses. To quantify the relative macroalgal removal by each species of herbivore at different times of the year, the total number of bites taken by each herbivorous fish species was recorded from the video footage for the entire $4.5 \mathrm{~h}$ of each trial. Consecutive bites on the algae without discernable pause were conservatively recorded in terms of forays, where one foray equals a single bite (following Bellwood \& Choat 1990). Bites were attributed to fishes in size categories for each species $(5 \mathrm{~cm}$ increments for individuals $>10 \mathrm{~cm}$, and $2.5 \mathrm{~cm}$ increments for individuals $<10 \mathrm{~cm}$ ). The total number of bites per fish species was then converted to a standardized bite impact (total number of bites $\times$ body mass in $\mathrm{kg}$ ) using published length-weight relationships (Kulbicki et al. 2005) to take into account differences in fish size, with fish length taken as the midpoint of the respective size class.

Roving herbivore censuses. To evaluate the extent of time-of-year variation in herbivore abundance and biomass across the study sites, herbivorous fish abundances were quantified every 2 mo using underwater visual censuses. To minimize disturbance, four 5-min timed swims were conducted at each site $(n=8)$. Each census consisted of 2 divers swimming simultaneously and parallel to the reef crest. The first diver recorded all herbivores $>10 \mathrm{~cm}$ in total length (TL) in a $5 \mathrm{~m}$ wide transect, and the second diver recorded individuals $<10 \mathrm{~cm}$ TL in a $1 \mathrm{~m}$ wide transect (following Bellwood $\&$ Wainwright 2001). Fish were grouped in size categories as above (individuals $<5 \mathrm{~cm}$ were not recorded). The total distance of each census was estimated using an average of 5 measured swims and observed abundances were standardized to a $250 \mathrm{~m}^{2}$ area, which permitted the data to be converted to abundances per unit area. Abundance estimates were then converted to biomass estimates using published length-weight rela- 
tionships for each species (Kulbicki et al. 2005), with fish length taken as the midpoint of the respective size class.

The species included in this study were roving (mobile) and 'nominally' herbivorous fishes (sensu Choat et al. 2002). This included members of the families Acanthuridae, Ephippidae, Kyphosidae, Labridae (parrotfishes) and Siganidae. A total of 43 species within these 5 families have been previously reported from Pioneer Bay (Bellwood et al. 2006). For the purpose of this study, it was decided to base the quantification of herbivory on the roving component only, excluding site-attached, territorial herbivores of the families Bleniidae, Gobiidae and Pomacentridae. Although these families are highly abundant on reefs, their contribution to the overall biomass of herbivores is considerably smaller than that of the roving component (Ceccarelli et al. 2001, Depczynski \& Bellwood 2003, Wilson et al. 2003). Furthermore, roving herbivores have been reported to have a significantly greater impact on benthic community structure than site-attached species (Ceccarelli et al. 2005b). In addition to visual censuses, the presence of key Sargassum-removing fish species was recorded during the video analyses to determine if these species with a strong negative response to divers were present regardless of their feeding activities.

Statistical analyses. Variation in rates of macroalgal removal by herbivorous fishes at different times of the year (in terms of standardized percentage decreases in biomass and length of Sargassum strands) were analysed using 2-way ANOVAs, with site and month treated as fixed factors. Assumptions of normality and homogeneity of variance were inspected via residual plots and in all cases data were arcsine- (to account for the use of proportional data) and square-roottransformed in order to meet the assumptions. The analyses of macroalgal removal by herbivores detected no significant effect of site (Table 1); therefore, data were pooled across the 2 sites for presentation.

Analysis of the mass-standardized bite impact of individual herbivorous fish species revealed 6 dominant species that had $>3000$ standardized bites (i.e. $3000 \mathrm{~kg} \times$ bites) on macroalgae over the sum of all feeding trials. The remainder of reef fish species had substantially <1000 standardized bites and were therefore removed from further analysis (see Figs. S1 \& S2 and Table S1 in the Supplement at www.int-res. com/articles/suppl/m422p239_supp.pdf). There was no effect of site on the total number of bites per species recorded by the video analyses and no significant interaction between site and month; therefore, data were pooled across the 2 sites for presentation and all subsequent comparisons conducted at the month level.

To characterize temporal trends in herbivory, a non-metric multidimensional scaling (NMDS) analysis was used to examine the relative contribution of individual herbivorous species at different time of year (based on bite impacts of herbivorous fish). This analysis was performed on the Bray-Curtis similarity matrix calculated from the mean number of massstandardized, $\log (x+1)$-transformed bite impact of the 6 dominant species per month at each site (3 days per month; $12 \mathrm{mo}$ ). The significance of the contribution of each species was displayed as vectors on the nMDS ordination plot. The lengths of the vectors were set proportional to the $\mathrm{R}^{2}$ obtained in the analysis and their direction indicated the direction of greatest increase of the variable (Wilson \& Sheaves 2001). To increase the interpretation of the NMDS and provide an objective description of the month grouping, a statistical classification using a 2-way analysis of similarity (ANOSIM) was superimposed on the ordination (Faith et al. 1987). This analysis was again based on Bray-Curtis similarity coefficient matrix, calculated from the standardized, $\log (x+1)$ transformed bites impact data.

\section{RESULTS}

\section{Removal rates}

Rates of macroalgal removal revealed marked variation in levels of herbivory among months (Fig. 1, Table 1). The highest removal rates were observed during January and April, and again from August to December, with assays typically exhibiting an average monthly removal of 70 to $90 \%$ decrease in biomass over $4.5 \mathrm{~h}$. The lowest rates in macroalgal removal occurred during the cooler period (June to July), with average decreases in biomass between 15 and $30 \%$. Decreases in Sargassum length followed a similar pattern (Table 1). 


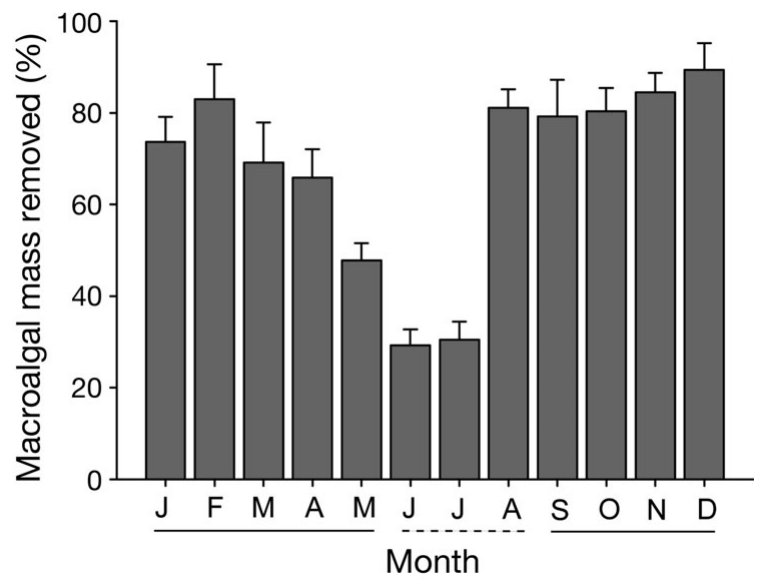

Fig. 1. Proportion of initial Sargassum mass removed (\%) by herbivores over a $4.5 \mathrm{~h}$ period (allowing for deployment loss). Data are mean $+\mathrm{SE}(\mathrm{n}=6$ per month). $x$-axis: - warm months, -.-- cold months

\section{Temporal patterns in herbivore distribution}

A total of 1836 individual roving herbivores of 17 different species and 5 reef fish families were recorded during visual censuses (Acanthuridae, Ephippidae, Kyphosidae, Labridae and Siganidae). The biomass of the 17 species of herbivorous fishes was strongly dominated by 3 species: Chlorurus microrhinos, Scarus rivulatus and Siganus doliatus. These 3 species made up an average of $62.8 \%$ of the total biomass of roving herbivorous fishes (Fig. 2). There were no apparent temporal trends in the distribution and total biomass of herbivorous fishes over the months (60.2 to $79.1 \mathrm{~g} \mathrm{~m}^{-2}$; Fig. 2). Similarly, video censuses of fish present in the assay area (regardless of feeding activity) revealed Kyphosus vaigiensis and Naso unicornis to be present in both warm and cool months (see Table 1 in the Supplement).

\section{Species impact}

A total of 15 nominally herbivorous reef fish species were observed feeding on Sargassum. These fishes included members of the families Acanthuridae (Acanthurus spp. and Naso unicornis), Kyphosidae (Kyphosus vaigiensis), Labridae (parrotfishes) (Scarus rivulatus and Scarus spp.) and Siganidae (Siganus doliatus) (see Fig. S2 in the Supplement). However, of the 111798 bites taken from transplanted assays, more than two-thirds $(\sim 77 \%$ of the total recorded bites; 85635 bites) were attributable to $K$. vaigiensis (a species rarely recorded during the visual censuses). Two other species $(N$. unicornis and the visually dominant $S$. doliatus) accounted for the majority (18\%) of the remaining $23 \%$ of the total bites taken from Sargassum assays throughout the study period.
The patterns of mass-standardized bite impacts of the 3 dominant species removing Sargassum were examined in greater detail to determine temporal patterns in levels of herbivory (Fig. 3). Significant variation in the feeding pattern of herbivores was observed throughout the 12 mo study period. Feeding activity on Sargassum transplants by Kyphosus vaigiensis was restricted to the warmer months, between February to May and again from August to December (Fig. 3a). There was almost no feeding by $K$. vaigiensis on Sargassum in June and July, although the fishes were present in the immediate vicinity of the assays (see Table S1 in the Supplement). Naso unicornis displayed a relatively uniform feeding rate among months, but with a low number of standardized bites, although maximum feeding activity on Sargassum was observed from September to December (Fig. 3b). A markedly different pattern was observed in the number of standardized bites taken by Scarus rivulatus, Acanthurus spp. and Scarus spp. among months (Fig. 3d-f). Indeed, in contrast to $K$. vaigiensis, which feeds on Sargassum primarily in warm months, these species concentrated their feeding activities on Sargassum in the cooler months (May to July). However, despite this activity, these herbivores had only a limited impact on algae removal during the cool period. Although they were responsible for most algal removal, only 15 to $30 \%$ of the total biomass of Sargassum was removed at this time of year (and only a 10 to $20 \%$ decrease in length) (Fig. 1). It should also be noted that because of the fragility of the algae, the loss of blades in the winter

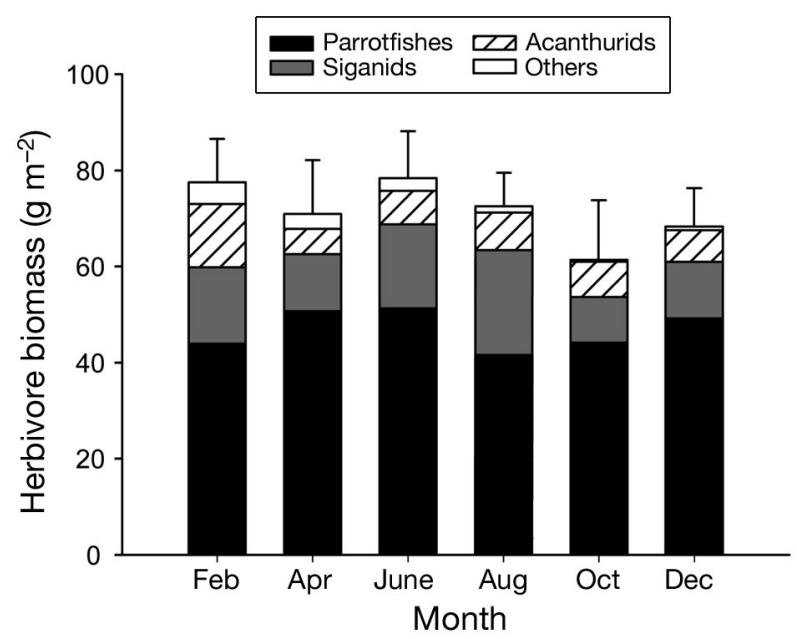

Fig. 2. Distribution of total herbivore biomass $\left(\mathrm{g} \mathrm{m}^{-2}\right)$ estimated from 5 min underwater visual censuses on the reef crest. Herbivore biomass is separated into contributions from parrotfishes, siganids, acanthurids and 'others', where 'others' represents the contribution of the remaining species of roving herbivorous fishes recorded in the visual censuses (namely, Kyphosus cinerascens, $K$. vaigiensis and Platax pinnatus). Error bars represent $+\mathrm{SE}$ of total herbivore biomass $(\mathrm{n}=8$ censuses per month; $\mathrm{n}=48$ in total) 

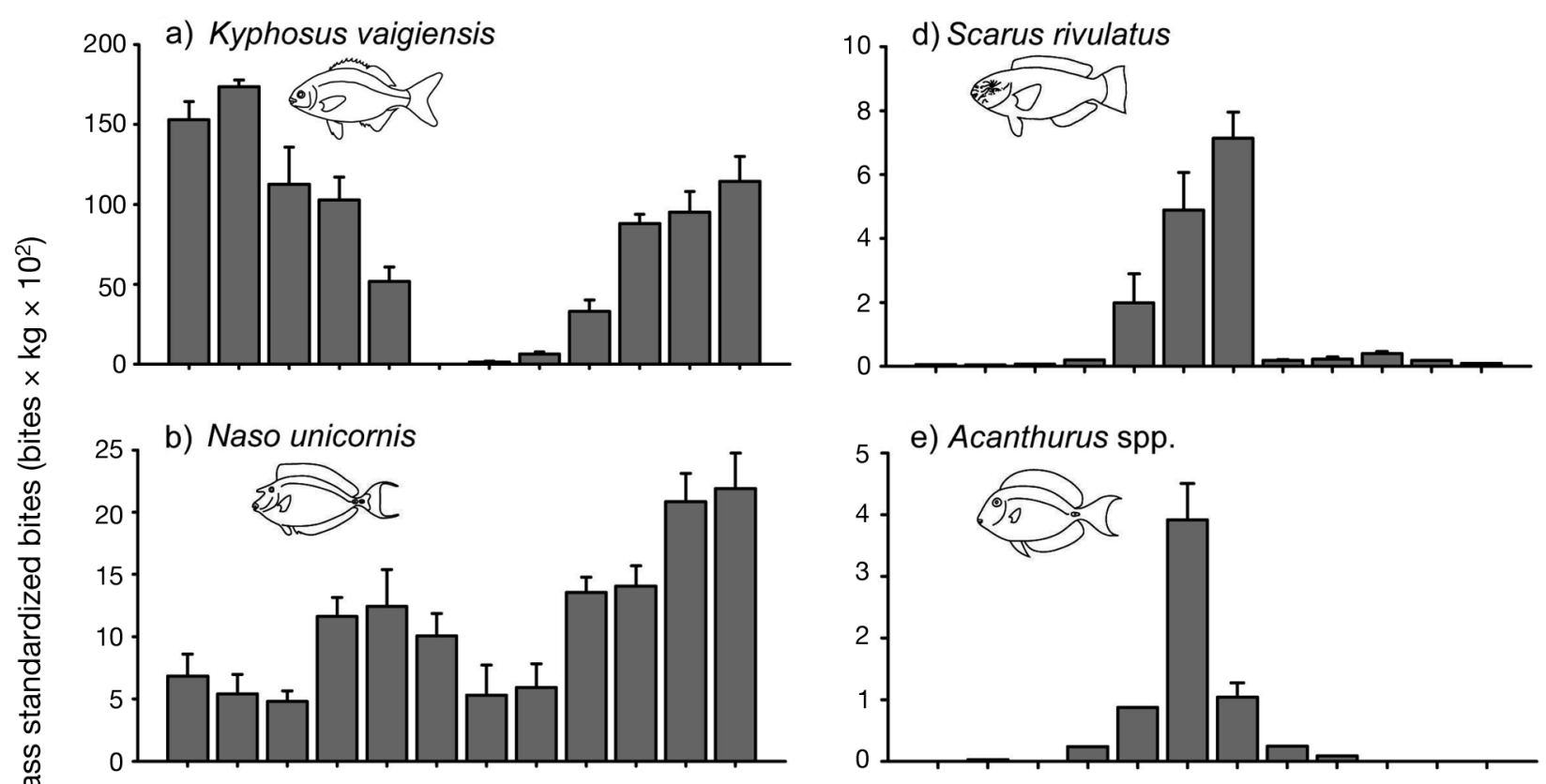

e) Acanthurus spp.
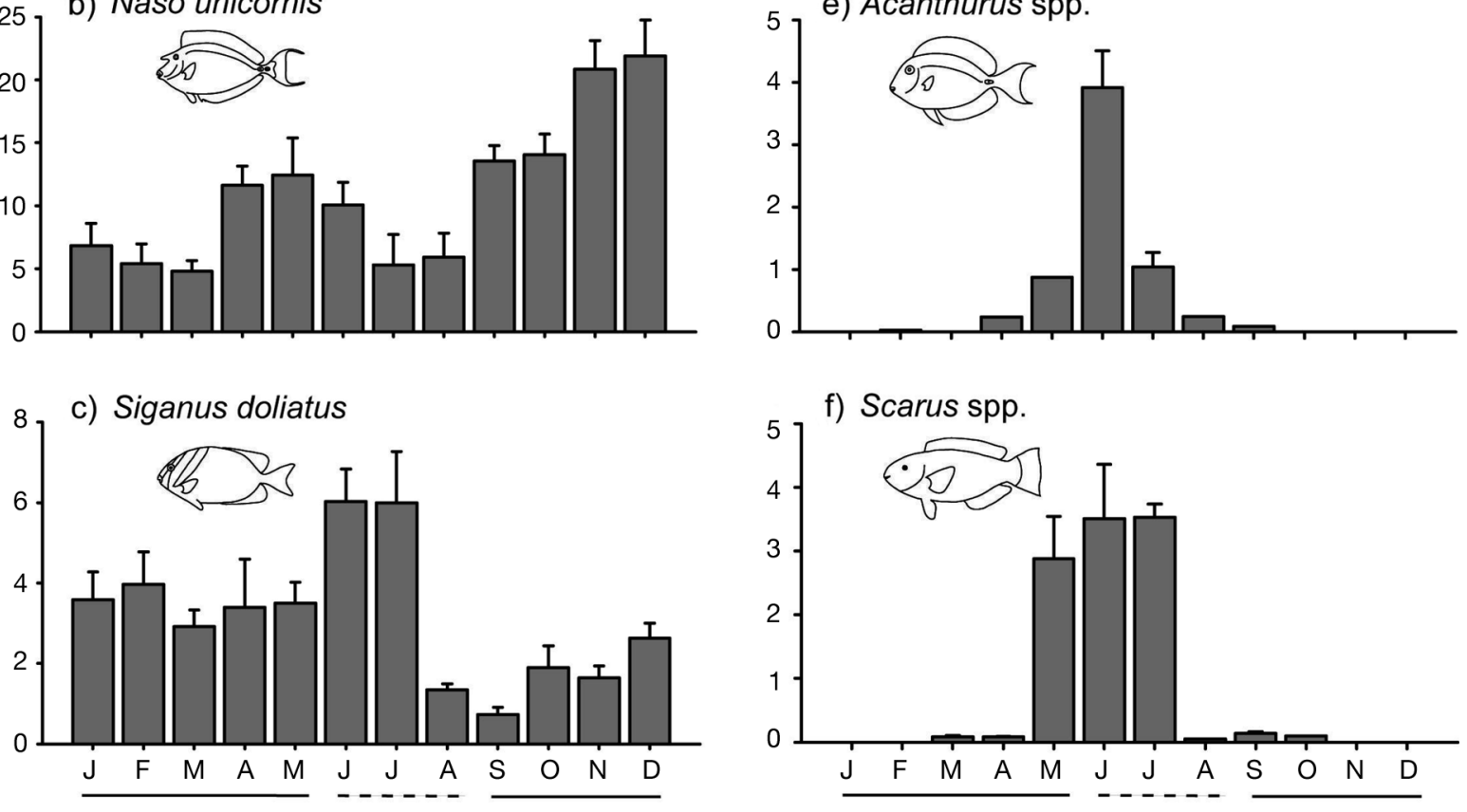

Month

Fig. 3. Mean number of mass-standardized bites (total bites $\times$ body mass in kg) on macroalgae per month at each site for (a) Kyphosus vaigiensis, (b) Naso unicornis, (c) Siganus doliatus, (d) Scarus rivulatus, (e) Acanthurus spp. and (f) Scarus spp. (S. flavipectoralis, S. ghobban and S. schlegeli). Note the difference in magnitude for $K$. vaigiensis and to a lesser extent $N$. unicornis in comparison to the other species. Data are standardized by fish weight according to published length-weight relationships. Data are mean + SE $(n=6$ per month). $x$-axis: — warm months, ---- cold months

may also reflect handling or dislodged material rather than direct herbivory. The remaining species, Siganus doliatus, showed no strong temporal patterns in feeding intensity, and the number of standardized bites fluctuated throughout most of the study period (Fig. 3c). However, from August onwards, there appears to be a decrease in feeding levels.

The results of the NMDS analysis supported this general temporal trend, identifying strong variations among months in feeding activity (Fig. 4). There appears to be a major division between the warmer and the cooler months. There was little separation evident between sites in the same month. ANOSIM analysis revealed significant differences between the warm and cool months (Fig. 4a), further supporting this strong separation between these 2 very distinct times of year (global $R=0.910$, significance level $0.1 \%$ ). The basis of the division between warm and cool months, as revealed by the NMDS species contribution biplot, was the distinct separation of the months driven by the feeding activity of Kyphosus vaigiensis and, to a lesser extent, Naso unicornis (Fig. 4b). This warm month feeding contrasted with the cool months, which were characterized by high feeding rates of Scarus rivulatus, Acanthurus spp. and Scarus spp.

\section{DISCUSSION}

The removal rates of Sargassum transplants in Pioneer Bay showed marked temporal variation in herbivory, with significantly higher rates of feeding by 
herbivores recorded during the summer period and almost insignificant levels of macroalgal removal during the winter period. These dramatic changes in the amount of material removed reflect a considerable decrease in herbivore activity underpinned by a distinct separation of species involved in this reef process between warm and cool periods. The video analyses yielded interesting insights into the process of herbivory in Pioneer Bay. The high levels of temporal variability in Sargassum removal rates and the basic division between the warm and cool months appears to be driven primarily by variation in the feeding activity on Sargassum of a single herbivorous fish species, $K y$ phosus vaigiensis. During the summer months, 83\% (85553 bites) of the total standardized bites on Sargassum were attributable to $K$. vaigiensis. However, there was an almost total cessation of feeding by this species on Sargassum assays deployed during winter months (82 bites).

\section{Temporal trends in removal rates by herbivores}

Our findings raise several questions about the ecology and feeding behaviour of Kyphosus vaigiensis, specifically why its impact on benthic macroalgae varies over time. Literature on kyphosid ecology on coral reefs is relatively scarce, as much of the research has concentrated on subtropical regions where they achieve their highest abundance (discussed in Cvitanovic \& Bellwood 2009). With the exception of a recent study on Orpheus Island (Cvitanovic \& Bellwood 2009), the potential for members of the family Kyphosidae to remove brown macroalgae has previously been based primarily on dietary studies (e.g. Clements \& Choat 1997, Choat et al. 2002, 2004, Ferreira et al. 2004, Silvano \& Guth 2006). Although these dietary analyses have suggested that the dominant component in their diet was brown thallate macroalgae, it consisted predominantly of Turbinara and Dictyota, with no evidence of Sargassum ingestion. The dominant presence of these macroalgal genera in the diet of $K$. vaigiensis in these earlier studies may be explained by the fact that Turbinara and Dictyota were the 2 most abundant genera of brown fleshy macroalgae present at the sampling sites, which were situated on mid- and outer-shelf reefs on the GBR (e.g Choat et al. 2002, 2004). Beyond this dietary work, however, there has been little investigation of the significance of the kyphosids in coral reef herbivory. In a study of 3 bays on Orpheus Island, Cvitanovic \& Bellwood (2009) suggested that the role of kyphosids in removing Sargassum may be much more important than originally thought. However, as previously pointed out by Paddack et al. (2006), kyphosids have rarely been
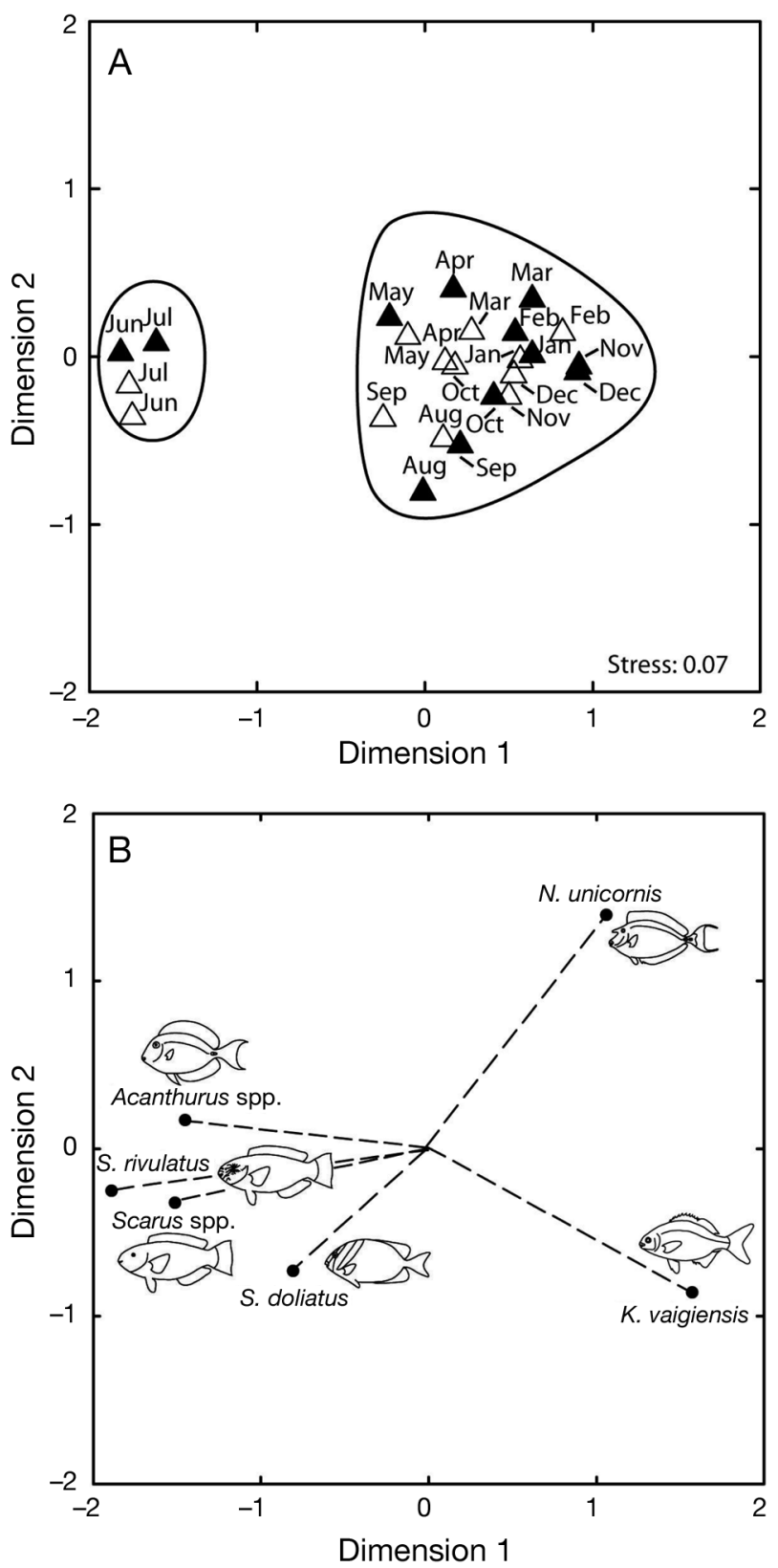

Fig. 4. Relative contribution of individual herbivorous species at different times of year. (a) Two-dimensional plot of a nonmetric multidimensional scaling analysis (NMDS) showing the temporal variation in number of bites taken by each herbivorous species at the 2 different sites (stress value $=0.07$ ). Each month includes 2 sites (open and filled triangles). Ellipses represent significant groupings identified by ANOSIM. (b) Biplot of the relative contribution of each herbivorous species to the observed differences in month groupings. Vectors represent the correlation of the original variables (standardized bites per species) with the first 2 NMDS dimensions. Vector lengths are proportional to the squared multiple correlation coefficient $\left(\mathrm{R}^{2}\right)$. Species names: Acanthurus spp., Kyphosus vaigiensis, Naso unicornis, Scarus rivulatus, Scarus spp. and Siganus doliatus 
observed feeding on benthic macroalgae; however, they often feed on drifting macroalgae at the surface. The present results suggest that kyphosids can feed on benthic macroalgae, and reinforce the suggestion that visual censuses may not adequately represent herbivore impact and the role of herbivores in reef processes (Bellwood et al. 2006, Fox \& Bellwood 2008b, Hoey \& Bellwood 2009). Although in general agreement with the observations of Cvitanovic \& Bellwood (2009), warm month Sargassum removal rates in the present study were almost double those reported by these authors. The present study had rates of removal of approximately $85 \%$ in a $4.5 \mathrm{~h}$ period whereas Cvitanovic \& Bellwood (2009) reported less than $45 \%$ removal after a $3 \mathrm{~h}$ period of exposure to herbivorous fishes. Moreover, in the present study, $K$. vaigiensis was almost always observed in large schools of 25 to 30 individuals feeding simultaneously during the summer months (maximum of 50 individuals). This further highlights the importance of kyphosids in maintaining warm month reef processes and their key role in shaping variation in browsing rates.

The nasiid surgeonfish Naso unicornis was found to have less impact on the decrease in macroalgal biomass. However, these results must be interpreted with caution. The disproportionate impact observed between Kyphosus vaigiensis and $N$. unicornis may be the consequence of the low abundance of nasiid surgeonfish in Pioneer Bay. Indeed, N. unicornis were most frequently observed feeding individually on Sargassum assays with a maximum of just 3 individuals at a time. These individuals were predominantly large fish (often $>40 \mathrm{~cm}$ TL; compared with kyphosids which were usually $<30 \mathrm{~cm}$ TL) but the limited impact was probably a result of low local densities. Although $N$. unicornis had a smaller influence on the removal of macroalgae, they seem to have great potential in removing Sargassum off the reef in other GBR locations where they occur in greater densities (Russ 1984, Hoey \& Bellwood 2009, 2010b).

\section{Factors influencing temporal patterns in herbivory}

The rate of macroalgal feeding intensity on coral reefs cannot be considered a static process. As recorded herein, distinct temporal patterns in herbivore feeding pressure may occur. Several factors may underpin this variation. They include (1) the availability of fishes (change in herbivore biomass), (2) the availability and quality of other food sources, (3) the presence of predators and (4) variation in the biomass, size and condition of macroalgae. Paddack et al. (2006) reported large fluctuations in herbivorous fishes on reefs off Florida, resulting in temporal variation in esti- mated algal consumption rates. These high temporal and spatial variations were mainly driven by the intermittent presence of large schools of Kyphosus sectatrix and Scarus coelestinus. In the present study, however, there was no indication of fluctuations in herbivorous reef fish biomass over the course of this study and both kyphosids and scarids were seen throughout the course of the study (Kyphosus vaigiensis, although not recorded during visual censuses, was regularly seen on video observations during both the summer and winter periods; see Table S1 in the Supplement). Another potential factor that could explain these distinct temporal patterns in herbivory is the availability of other food sources in the vicinity, as noted by Hoey \& Bellwood (2010b) on the northern GBR. However, no other brown thallate macroalgae (such as Turbinara) were observed in significant densities in the Orpheus Island study area. Changes on the reef flat reported by Lefèvre \& Bellwood (2010) were outside the feeding areas of the main browsing fishes (hence the large algal strands), whereas Hughes et al. (2007) reported no changes in algal cover on the reef crest at Orpheus Island, the only location where kyphosids have been reported feeding at this site. In addition, the densities of other algal communities were generally low at the study sites across all habitats. Indeed, in contrast to macroalgae, benthic algal communities such as turf algae are typically low on inshore reefs of the GBR (e.g. Price 1989, Wismer et al. 2009). Although present on the reef slope, reef crest and outer reef flat, several studies have shown that turf algae had no significant variation of biomass over the year (e.g. Wilson et al. 2003, Fox \& Bellwood 2007). Hughes et al. (2007) also reported no variation in benthic algal communities over a 3 yr study on the reef crest at Orpheus Island, suggesting that the behaviour of the herbivores and detritivores in this study is unlikely to be caused by major changes in other food sources. We therefore have no evidence of changing algal composition in the areas where kyphosids are known to forage. Nevertheless, the changing availability of algae in other unknown locations cannot be discarded as a significant contributing factor.

Alternatively, changes in predation pressure may also explain the observed patterns. Although the present study did not specifically measure variation in predator biomass, there was no obvious change in predation pressure throughout the course of the study. Several studies have documented that no-take marine reserves had significantly higher density and greater biomass of large predatory reef fishes than in fished locations (e.g. Russ 2002, Halpern 2003, Evans \& Russ 2004). Although no instances of predation were witnessed, large piscivores, including Caranx ignoblis, Carcharinus melanopterus and Triaenodon obesus, 
were observed throughout the present study. As Kyphosus vaigiensis was present throughout the year, it appears that it is not fish presence or absence but feeding activity that shaped rates of herbivory.

Finally, one must consider the variation in size and condition of Sargassum. This appears to be the major factor influencing herbivore feeding behaviour (see Lefèvre \& Bellwood 2010 for a full discussion of Sargassum condition in relation to the variation in macroalgal removal). This variation appears to shape not only the rate of removal but also the species responsible for macroalgal removal. The size of transplants seems to have a minor influence as the same herbivores were observed to feed on bioassays from 10 to $120 \mathrm{~cm}$ (these included Kyphosus vaigiensis, Naso unicornis and Siganus doliatus). Furthermore, mature and dense canopies had rates of removal very similar to that of short and regrown Sargassum (in February-April and August-October, respectively). Secondary metabolites, which may deter feeding by fishes, may also help explain the observed patterns. Indeed, the algal species used in this study possess both chemical and morphological defences (e.g. Littler et al. 1983). Such defences have traditionally been associated with high susceptibility to grazing by herbivores (Hay \& Fenical 1988).

Chemical defence may also have indirect effects. Senescence of Sargassum (i.e. when most of the photosynthetic tissues are lost) may leave the remaining plant materials with insufficient resources for defence against epiphytes. In fact, senescence has often been attributed to a decrease in secondary metabolites after reproduction (McCook 1996), which may explain the increase in epiphyte cover during the winter months. However, if herbivores were repelled by chemical defences, one might expect higher rates of removal of Sargassum during the winter months, when concentration of deterrents is relatively low. Yet feeding rates were significantly greater during the summer months. This suggests that marine plant chemical defences may not be influencing feeding behaviour by reef fishes to any great extent.

Another possible explanation to the observed patterns is the low nutritional value of macroalgae and the variation of carbon and nitrogen contents in Sargassum tissues over the year. However, variation in feeding intensity of herbivorous fish has recently been reported to be uncorrelated with the variation in C:N in Sargassum plants throughout the year (Lefèvre \& Bellwood 2010). Furthermore, kyphosids possess a large and muscular stomach with a small hindgut chamber that allows them to break down macroalgae. They are one of the few marine herbivores that can derive adequate nutrition from macroalgae through a process of microbial fermentation (Clements \& Choat
1997, Moran \& Clements 2002, Crossman et al. 2005). Thus, of all species, kyphosids appear to be relatively insensitive to changes in $\mathrm{C}: \mathrm{N}$ ratios.

Overall, it appears that Kyphosus vaigiensis is not greatly affected by the size of Sargassum, nor by its chemical defences and low nutritional value, but rather from the variation in the condition of algae over the year. Indeed, perhaps the most obvious explanation for both a total absence of feeding by kyphosids and a simultaneous increase in grazing intensity by scarids is the heavily epiphytic condition of Sargassum during the winter months (Lefèvre \& Bellwood 2010). Indeed, parrotfishes may be targeting the epiphytic food sources growing on the algae rather than the Sargassum itself. This explanation is strongly supported by the present study, where results indicate that parrotfishes grazing on Sargassum have a substantially lower impact compared with kyphosids and nasos. In winter months, parrotfishes showed a strong increase in feeding rates but the contribution of these species was found to be insignificant compared with loss of biomass in other months. This applies equally to Siganus doliatus; this species has previously been demonstrated to have an insignificant impact on Sargassum biomass even when apparently feeding on the algae (Fox \& Bellwood 2008b). Furthermore, S. doliatus showed a pronounced decrease in macroalgal feeding intensity from August to December, when Sargassum thalli were clean from epiphytic algal material. The present results suggest that $S$. doliatus and $S$. rivulatus may be predominantly epiphyte feeders and that, although they feed on the surface of the Sargassum, these 2 species seem unlikely to influence general temporal trends in herbivory on Sargassum.

Interestingly, as reported herein, significantly more bites by parrotfishes on Sargassum were observed during the winter months. These results contrast markedly with earlier studies that reported strong avoidance of macroalgae by parrotfishes (e.g. Choat et al. 2002, Mantyka \& Bellwood 2007, Bonaldo \& Bellwood 2008). Indeed, recent evidence suggests that scarids have only a limited capacity to graze large or established macroalgae such as Sargassum (e.g. Bellwood et al. 2006). However, the present findings suggest that coral reef ecosystem processes may rely on parrotfishes, if only for a restricted period of time, as they may be the only species that target macroalgae during the winter and, as such, may perform a crucial role in preventing the dominance of Sargassum on reefs. Indeed, the interaction between Sargassum and parrotfish is noteworthy because it hints at the possibility that shifts to higher abundance of macroalgae may be dependent on scarids grazing, in the event of a loss of 'warm month herbivores'. For example, Hughes et al. (2007) demonstrated that the exclusion of large herbivores 
including parrotfishes caused a dramatic increase in algal biomass and, as expected, the species composition of macroalgae diverged markedly into a dense canopy of Sargassum (up to $3 \mathrm{~m}$ in height). However, the Sargassum population inside the cages did not show marked seasonal patterns, as one would have expected based on adjacent populations (Lefèvre \& Bellwood 2010). Instead, the algal cover increased steadily over the $3 \mathrm{yr}$ period of the caging experiment. Therefore, if scarids are the only herbivore feeding on macroalgae during winter, the system may rely on these fishes to reduce macroalgal cover during the cooler months to prevent establishment of Sargassum before the next reproductive season. In the absence of these scarids in the exclusion cages, Sargassum continued to grow unabated for $3 \mathrm{yr}$ (Hughes et al. 2007). Because all herbivore species were excluded, the question remains whether Scarus rivulatus is a 'driver' shaping Sargassum populations or simply a 'passenger' responding to available epiphytes and basically just eating 'dead' algal materials. Either way, parrotfishes have an unusual interaction with cool season, epiphyte-laden Sargassum.

In a similar vein, it is noteworthy that the majority of previous studies have used methods that are broadly comparable with those of the present study and have reported similar results in macroalgal biomass removed over the warm period. Each study had attributed most of the macroalgal biomass decrease to a single herbivore species, but these species differ in almost every study (Table 2). These paradoxical findings warrant further investigations on the feeding behaviour of herbivores. Nevertheless, the differences are informative and suggest that, instead of a single threshold or shifting point from coral to macroalgal dominance, there may be several intermediate states on the trajectory to an undesirable macroalgal-dominated reef and that the herbivorous fish species that may be capable of preventing the process of reef degradation to macroalgal dominance may change under each of those alternate states.

Additionally, until now, functional roles of the herbivore assemblage have always been assumed to remain constant over the year. However, as highlighted in the present study, it appears that functional roles are not uniform. Rather, individual species play functional roles that can be temporally very restricted. The feeding behaviour of Scarus rivulatus in the present study, for instance, suggests that although parrotfishes may be predominantly grazing on the EAM during most of the year, they may also play a restricted yet valuable role in preventing the proliferation of Sargassum on reefs under certain conditions. The system may rely on scarids, for only 2 months in the year, to reduce the biomass of Sargassum that is heavily coated with epi- phytic materials. Similarly, and to a much greater extent, the role of kyphosids in removing Sargassum appears to be strictly restricted to summer months, when macroalgae are healthy and clean. Although 43 herbivorous reef fish species have been reported in Pioneer Bay (Bellwood et al. 2006), it appears that there are only 3 key species when it comes to fulfilling specific functional roles over the year. The dominance of these 3 species in removing Sargassum suggests that the reef system in Pioneer Bay clearly displays limited functional redundancy in terms of species removing macroalgal at any given time of the year. The results presented herein have important ramifications for the structure of coral reef communities, suggesting that the key herbivore species of a particular reef are likely to change between different times of year reflecting changes in macroalgae condition.

Furthermore, the temporal variation in feeding behaviour and intensity of individual herbivores has interesting implications for coral reef resilience. Firstly, these findings suggest that, in the case of several intermediate states on the trajectory from a healthy coral-dominated reef to an undesirable macroalgaldominated reef, different herbivore species are responsible for the removal of macroalgal populations in each state, as previously suggested (Bellwood et al. 2006, Hoey \& Bellwood 2009). Sargassum dominance and persistence may thus depend upon the local abundance of a range of herbivore species with each one playing a different role. We may thus have multiple points of potential weakness where phase shifts may be triggered (a lack of cool month feeding activity may enhance summer populations) or reversed (extreme winter feeding may limit the summer regrowth). The crucial question now is to determine whether such small-scale interactions reflect seascape-scale processes. In addition, the findings of the present study imply that coral reef systems may be able to revert to their original assemblages through herbivorous fish activity that may be restricted to limited periods of the year. However, with the potential loss of key functional species, coral reef systems may have changed to the extent that they can no longer successfully recover to their original state even if herbivores appear to be active during most of the year. The recovery may therefore follow a different trajectory from that observed during the transition from a healthy to a macroalgal-dominated reef (hysteresis; sensu Hughes et al. 2005).

A few preliminary insights into these crucial issues have been highlighted in this study, and the results suggest that macroalgal removal can vary substantially at different times of year, emphasizing the distinction between warm and cool month reef processes. Although previous warm-season work on the overall 


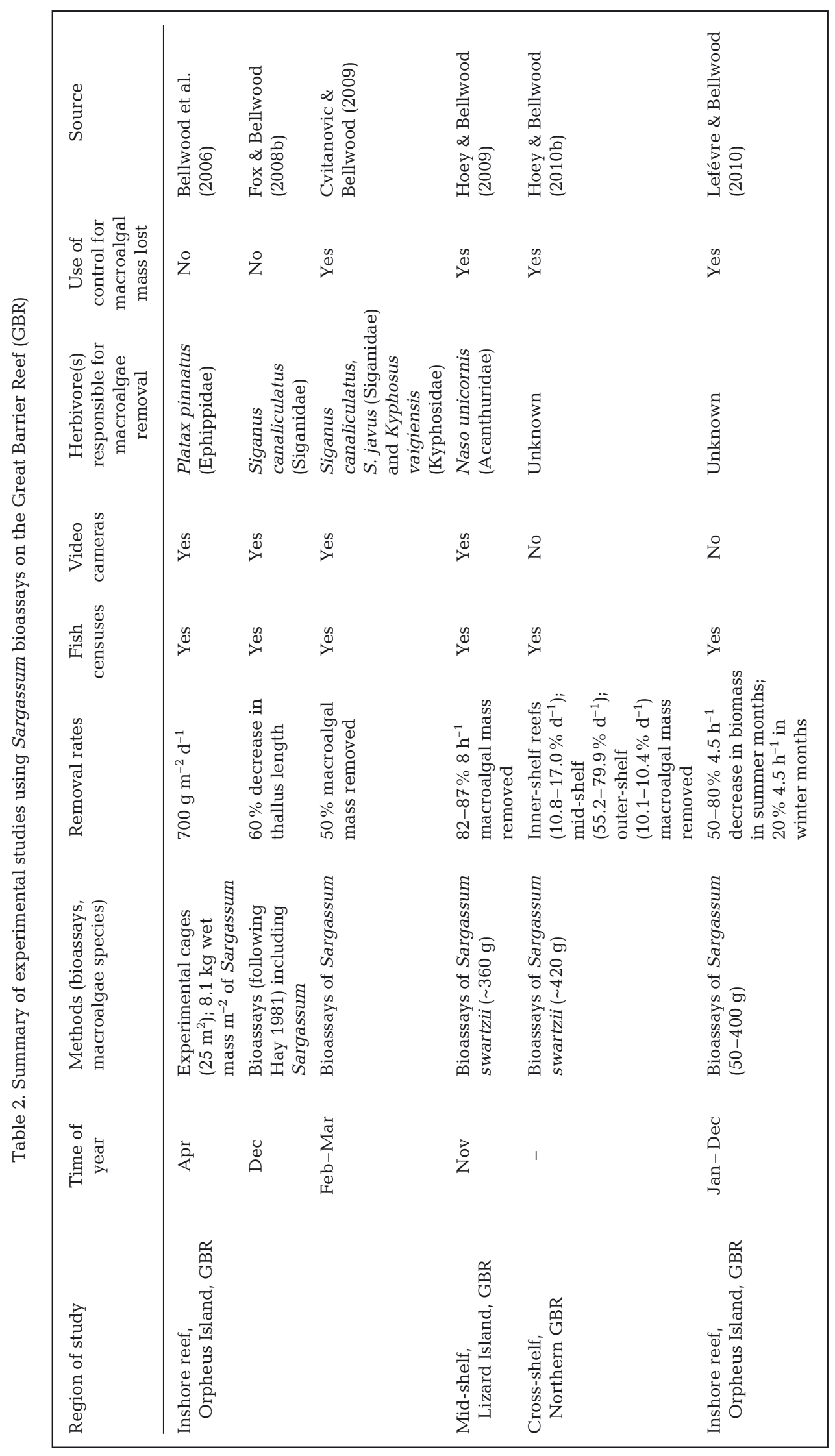


patterns of coral reef herbivory has provided similar results in terms of macroalgal material removed so far, results may differ greatly at other times of year. More importantly, the individual fish species actually responsible for the impacts being measured as herbivory can display very different feeding activity patterns on a temporal scale and may therefore have ecologically separate functional roles. This difference is instructive. Despite the fact that isolated Sargassum bioassays may not be representative of all aspects of herbivory, they highlight the potential effects of these herbivorous species at varying stages on macroalgal condition, succession and reef degradation, and also the importance of species richness in maintaining ecological function on these reefs. These species may have different and complementary roles in preconditioning reefs to permit coral recovery following disturbance. Furthermore, in terms of enhancing reef resilience, it is not only the species composition of herbivore assemblages which is important but equally the diversity of responses of these species to environmental change in macroalgal condition (Bellwood et al. 2004). Understanding the impact of individual herbivorous species and how they may vary among stages of macroalgal succession are therefore crucial to the understanding of resilience and future trajectories of coral reefs. Perhaps the most important conclusion from this study is that one cannot assume uniform reef processes throughout the year.

Acknowledgements. We thank the staff of Orpheus Island Research Station for field support; S. Bennett, R. Bonaldo, R. Fox, A. González-Cabello, A. Hoey, S. Montanari, J. PlassJohnson and S. Wismer for field assistance; and A. Beresford, A. González-Cabello, M. Pratchett, R. Rowe, G. Russ, J. Tanner, J. Welsh, S. Wismer and 3 anonymous reviewers for helpful discussions or comments on the earlier drafts of the manuscript. This work was supported by the Great Barrier Reef Marine Park Authorities and the Australian Research Council (D.R.B).

\section{LITERATURE CITED}

Bellwood DR, Choat JH (1990) A functional analysis of grazing in parrotfishes (family Scaridae): the ecological implications. Environ Biol Fishes 28:189-214

Bellwood DR, Wainwright PC (2001) Locomotion in labrid fishes: implications for habitat use and cross-shelf biogeography on the Great Barrier Reef. Coral Reefs 20: 139-150

Bellwood DR, Hoey AS, Choat JH (2003) Limited functional redundancy in high diversity systems: resilience and ecosystem function on coral reefs. Ecol Lett 6:281-285

Bellwood DR, Hughes TP, Folke C, Nystrom M (2004) Confronting the coral reef crisis. Nature 429:827-833

Bellwood DR, Hughes TP, Hoey AS (2006) Sleeping functional group drives coral reef recovery. Curr Biol 16:2434-2439

Bonaldo RM, Bellwood DR (2008) Size-dependent variation in the functional role of the parrotfish Scarus rivulatus on the Great Barrier Reef, Australia. Mar Ecol Prog Ser 360:
$237-244$

Ceccarelli DM, Jones JP, McCook LJ (2001) Territorial damselfishes as determinants of the structure of benthic communities on coral reefs. Oceanogr Mar Biol Annu Rev 39:355-389

Ceccarelli DM, Jones GP, McCook LJ (2005a) Effects of territorial damselfish on an algal-dominated coastal coral reef. Coral Reefs 24:606-620

Ceccarelli DM, Jones GP, McCook LJ (2005b) Foragers versus farmers: contrasting effects of two behavioural groups of herbivores on coral reefs. Oecologia 145:445-453

Ceccarelli DM, Hughes TP, McCook LJ (2006) Impacts of simulated overfishing on the territoriality of coral reef damselfish. Mar Ecol Prog Ser 309:255-262

Choat JH (1991) The biology of herbivorous fishes on coral reefs. In: Sale PF (ed) The ecology of fishes on coral reefs. Academic Press, San Diego, CA, p 120-155

Choat JH, Clements KD, Robbins WD (2002) The trophic status of herbivorous fishes on coral reefs. I. Dietary analyses. Mar Biol 140:613-623

Choat JH, Robbins WD, Clements KD (2004) The trophic status of herbivorous fishes on coral reefs. II. Food processing modes and trophodynamics. Mar Biol 145:445-454

Clements KD, Choat JH (1997) Comparison of herbivory in the closely related marine fish genera Girella and Kyphosus. Mar Biol 127:579-586

Crossman DJ, Choat JH, Clements KD (2005) Nutritional ecology of nominally herbivorous fishes on coral reefs. Mar Ecol Prog Ser 296:129-142

Cvitanovic C, Bellwood DR (2009) Local variation in herbivore feeding activity on an inshore reef of the Great Barrier Reef. Coral Reefs 28:127-133

Depczynski M, Bellwood DR (2003) The role of cryptobenthic reef fishes in coral reef trophodynamics. Mar Ecol Prog Ser 256:183-191

Diaz-Pulido G, McCook LJ, Larkum AWD, Lotze HK and others (2007) Vulnerability of macroalgae of the Great Barrier Reef to climate change In: Johnson JE, Marshall PA (eds) Climate change and the Great Barrier Reef: a vulnerability assessment. Great Barrier Reef Marine Park Authority and Australian Greenhouse Office, Townsville, p 153-192

Evans RD, Russ GR (2004) Larger biomass of targeted reef fish in no-take marine reserves on the Great Barrier Reef, Australia. Aquat Conserv 14:505-519

> Faith DP, Minchin PR, Belbin L (1987) Compositional dissimilarity as a robust measure of ecological distance. Vegetatio 69:57-68

> Ferreira CEL, Floeter SR, Gasparini JL, Ferreira BP, Joyeux JC (2004) Trophic structure patterns of Brazilian reef fishes: a latitudinal comparison. J Biogeogr 31:1093-1106

Fox RJ, Bellwood DR (2007) Quantifying herbivory across a coral reef depth gradient. Mar Ecol Prog Ser 339:49-59

Fox RJ, Bellwood DR (2008a) Direct versus indirect methods of quantifying herbivore grazing impact on a coral reef. Mar Biol 154:325-334

Fox RJ, Bellwood DR (2008b) Remote video bioassays reveal the potential feeding impact of the rabbitfish Siganus canaliculatus (f: Siganidae) on an inner-shelf reef of the Great Barrier Reef. Coral Reefs 27:605-615

Graham NAJ, Wilson SK, Jennings S, Polunin NVC, Pijous JP, Robinson J (2006) Dynamic fragility of oceanic coral reef systems. Proc Natl Acad Sci USA 103:8425-8429

> Halpern B (2003) The impact of marine reserves: Do reserves work and does size matter? Ecol Appl 13:117-137

- Hay ME (1981) Spatial patterns of grazing intensity on a Caribbean barrier reef: herbivory and algal distribution. Aquat Bot 11:97-110 
Hay ME, Fenical W (1988) Marine plant-herbivore interactions: the ecology of chemical defence. Annu Rev Ecol Syst 19:111-145

Hixon MA, Brostoff WN (1996) Succession and herbivory: effects of differential fish grazing on Hawaiian coral-reef algae. Ecol Monogr 66:67-90

- Hoey AS, Bellwood DR (2008) Cross-shelf variation in the role of parrotfishes on the Great Barrier Reef. Coral Reefs 27 : $37-47$

Hoey AS, Bellwood DR (2009) Limited functional redundancy in a high diversity system: single species dominates key ecological process on coral reefs. Ecosystems 12: 1316-1328

> Hoey AS, Bellwood DR (2010a) Damselfish territories as a refuge for macroalgae on coral reefs. Coral Reefs 29: 107-118

Hoey AS, Bellwood DR (2010b) Cross-shelf variation in browsing intensity on the Great Barrier Reef. Coral Reefs 29:499-508

> Hughes TP (1994) Catastrophes, phase shifts, and large-scale degradation of a caribbean coral reef. Science 265: $1547-1551$

- Hughes TP, Baird AH, Bellwood DR, Card M and others (2003) Climate change, human impacts, and the resilience of coral reefs. Science 301:929-933

Hughes TP, Bellwood DR, Folke C, Steneck RS, Wilson J (2005) New paradigms for supporting the resilience of marine ecosystems. Trends Ecol Evol 20:380-386

Hughes TP, Rodrigues MJ, Bellwood DR, Ceccarelli D and others (2007) Phase shifts, herbivory, and the resilience of coral reefs to climate change. Curr Biol 17:360-365

- Hughes TP, Graham NAJ, Jackson JBC, Mumby PJ, Steneck RS (2010) Rising to the challenge of sustaining coral reef resilience. Trends Ecol Evol 25:633-642

Jackson JBC, Kirby MX, Berger WH, Bjorndal KA and others (2001) Historical overfishing and the recent collapse of coastal ecosystems. Science 293:629-638

Kilar JA, Hanisak MD, Yoshida T (1992) On the expression of phenotypic variability: Why is Sargassum so taxonomically difficult? In: Abbott IA (ed) Taxonomy of economic seaweeds with reference to some Pacific and Western Atlantic Species 3. California Sea Grant College, University of California, p 95-117

Kulbicki M, Guillemot N, Amand M (2005) A general approach to length-weight relationships for New Caledonian lagoon fishes. Cybium 29:235-252

Lefèvre CD, Bellwood DR (2010) Seasonality in coral reef algae: variation in condition and susceptibility to herbivory. Mar Biol 157:955-965

Littler MM, Littler DS, Taylor PR (1983) Evolutionary strategies in a tropical barrier reef system: functional-form groups of marine macroalgae. J Phycol 19:229-237

Mantyka CS, Bellwood DR (2007) Macroalgal grazing selectivity among herbivorous coral reef fishes. Mar Ecol Prog Ser 352:177-185

McClanahan TR, Muthiga NA, Mangi S (2001) Coral and algal changes after the 1998 coral bleaching: interaction with reef management and herbivores on Kenyan reefs. Coral Reefs 19:380-391

McClanahan TR, Sala E, Stickels PA, Cokos BA, Baker AC, Starger CJ, Jones SH (2003) Interaction between nutrients and herbivory in controlling algal communities and coral

Editorial responsibility: Tim McClanahan,

Mombasa, Kenya condition on Glover's Reef, Belize. Mar Ecol Prog Ser 261: 135-147

McCook LJ (1996) Effects of herbivores and water quality on Sargassum distribution on the Central Great Barrier Reef: cross-shelf transplants. Mar Ecol Prog Ser 139:179-192

McCook LJ (1997) Effects of herbivory on zonation of Sargassum spp within fringing reefs of the central Great Barrier Reef. Mar Biol 129:713-722

> Moran D, Clements KD (2002) Diet and endogenous carbohydrates in the temperate marine herbivorous fish Kyphosus sydneyanus. J Fish Biol 60:1190-1203

- Mumby PJ, Dahlgren CP, Harborne AR, Kappel CV and others (2006) Fishing, trophic cascades, and the process of grazing on coral reefs. Science 311:98-101

Nyström M, Folke C (2001) Spatial resilience of coral reefs. Ecosystems 4:406-417

Nyström M, Folke C, Moberg F (2000) Coral reef disturbance and resilience in a human-dominated environment. Trends Ecol Evol 15:413-417

> Paddack MJ, Cowen RK, Sponaugle S (2006) Grazing pressure of herbivorous coral reef fishes on low coral-cover reefs. Coral Reefs 25:461-472

> Pandolfi JM, Bradbury RH, Sala E, Hughes TP and others (2003) Global trajectories of the long-term decline of coral reef ecosystems. Science 301:955-958

Price IR (1989) Seaweed phenology in a tropical Australian locality (Townsville, North Queensland). Bot Mar 32:399-406

Reinthal PN, Macintyre IG (1994) Spatial and temporal variations in grazing pressure by herbivorous fishes: Tobacco Reef, Belize. Atoll Res Bull 425:1-11

> Russ GR (1984) Distribution and abundance of herbivorous grazing fishes in the central Great Barrier Reef. I. Levels of variability across the entire continental shelf. Mar Ecol Prog Ser 20:23-34

Russ GR (2002) Yet another review of marine reserves as reef fishery management tools. In: Sale PF (ed) Coral reef fishes: dynamics and diversity in a complex ecosystem. Academic Press, San Diego, CA, p 421-443

Russ GR (2003) Grazer biomass correlates more strongly with production than with biomass of algal turfs on a coral reef. Coral Reefs 22:63-67

Schaffelke B, Klumpp DW (1997) Biomass and productivity of tropical macroalgae on three nearshore fringing reefs in the central Great Barrier Reef, Australia. Bot Mar 40: $373-383$

Silvano RAM, Guth AZ (2006) Diet and feeding behavior of Kyphosus spp. (Kyphosidae) in a Brazilian subtropical reef. Braz Arch Biol Technol 49:623-629

Wilson J, Sheaves M (2001) Short-term temporal variations in taxonomic composition and trophic structure of a tropical estuarine fish assemblage. Mar Biol 139:787-796

Wilson SK, Bellwood DR, Choat JH, Furnas MJ (2003) Detritus in the epilithic algal matrix and its use by coral reef fishes. Oceanogr Mar Biol Annu Rev 41:279-309

> Wilson SK, Graham NAJ, Pratchett MS, Jones GP, Polunin NVC (2006) Multiple disturbances and the global degradation of coral reefs: Are reef fishes at risk or resilient? Glob Change Biol 12:2220-2234

> Wismer S, Hoey AS, Bellwood DR (2009) Cross-shelf benthic community structure on the Great Barrier Reef: relationships between macroalgal cover and herbivore biomass. Mar Ecol Prog Ser 376:45-54

Submitted: May 18, 2010; Accepted: November 2, 2010

Proofs received from author(s): January 24, 2011 